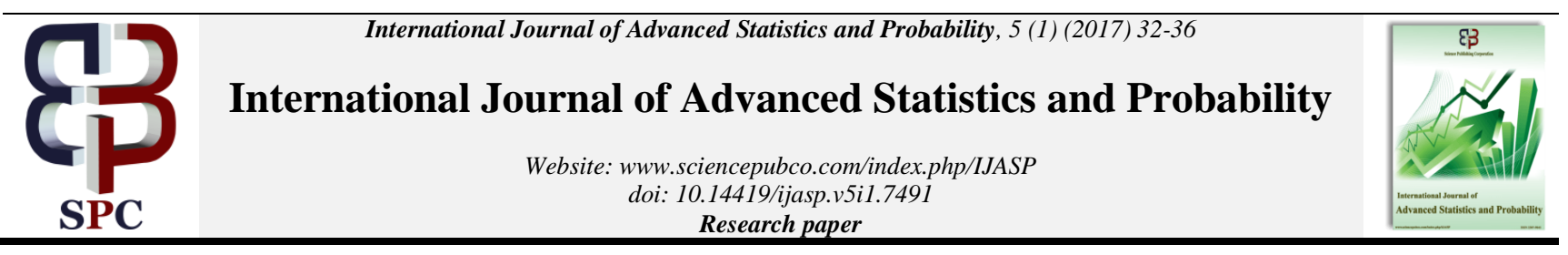

\title{
Precision of full polynomial response surface designs on models with missing coefficients
}

\author{
Iwundu, M. P ${ }^{1 *}$, Jaja, E. I. ${ }^{2}$ \\ ${ }^{1}$ Department of Mathematics and Statistics, University of Port Harcourt, Nigeria \\ ${ }^{2}$ Department of Mathematics and Statistics, Rivers State University, Nigeria \\ *Corresponding author E-mail: mary.iwundu@uniport.edu.ng
}

\begin{abstract}
The precision of using full polynomial response surface designs on models with missing coefficients (reduced models) is studied using efficiency measures. The loss in D- and G-efficiency of constructed first-order exact designs is minimized for the model with missing interaction coefficient. However, higher losses in D- and G-efficiency are recorded when constructed second-order exact designs are used on the model with missing interaction coefficient with few exceptions showing preferences for using the designs on the reduced model. Lower condition numbers are observed for the designs under the first-order reduced models thus indicating that the N-point exact designs are closer to being orthogonal for the reduced model than for the full model. Perfect orthoganality is achieved at design sizes 4 and 8 . In fact, $\mathrm{N}$-point exact designs of multiples of $\mathrm{N}=4$ show perfect orthoganality when defined either for the full or reduced first-order models. In comparison to a design with perfect orthoganality, the second-order designs are far from being orthogonal.
\end{abstract}

Keywords: Condition Number; Design Efficiency; Full Models; Reduced Models and Response Surface Designs.

\section{Introduction}

Polynomials have been suitably used as approximating functions for the true unknown functional models when describing the relationship between a response variable y and several control variables, $\mathrm{x}_{1}, \mathrm{x}_{2}, \ldots, \mathrm{x}_{\mathrm{k}}$. Following the notations of Khuri and Mukhopadhyay [8], the approximating polynomial model is of the form

$y=f^{\prime}(\underline{x}) \beta+\varepsilon$

where

$y$ is the vector of observations.

$\underline{\mathrm{x}}=\left(\mathrm{x}_{1}, \mathrm{x}_{2}, \ldots, \mathrm{x}_{\mathrm{k}}\right)$ is the design point defined on a Euclidean space.

$f(\underline{x})$ is a vector of $p$ elements that consist of powers of $\mathrm{x}_{1}, \mathrm{x}_{2}, \ldots, \mathrm{x}_{\mathrm{k}}$ up to a certain degree $\mathrm{d}(\geq 1)$.

$\beta$ is a vector of $p$ unknown coefficients called parameters and are estimated on the basis of $\mathrm{N}$ uncorrelated observations..

$\varepsilon$ is a random experimental error assumed to have a zero mean and constant variance $\sigma^{2}$.

The model in (1) may be re-expressed conventionally as

$$
\mathrm{y}=\mathrm{X} \beta+\varepsilon
$$

\section{where}

$\mathrm{X}$ is an $\mathrm{N} \times \mathrm{p}$ design matrix otherwise called model matrix.

$\beta$ is estimated as $\hat{\beta}=\left(X^{\prime} X\right)^{-1} X^{\prime} y$ using the least square approach. The variance of the estimate is

$\operatorname{Var}(\hat{\beta})=\sigma^{2}\left(X^{\prime} X\right)^{-1}$

$$
\mathrm{E}(\mathrm{y})=\mathrm{X} \hat{\beta}
$$

$\mathrm{V}(\hat{\mathrm{y}}(\underline{\mathrm{x}}))=\sigma^{2} \underline{\mathrm{x}}\left(\mathrm{X}^{\prime} \mathrm{X}\right)^{-1} \underline{\mathrm{x}}^{\prime}$

Two important approximating polynomial models commonly used in response surface methodology are the first-degree model, with $\mathrm{d}=1$, given as

$$
y=\beta_{0}+\sum_{i=1}^{k} \beta_{i} x_{i}+\varepsilon
$$

and the second-degree model, with $\mathrm{d}=2$, given as

$$
y=\beta_{0}+\sum_{i=1}^{k} \beta_{i} x_{i}+\sum \sum_{i<j} \beta_{i j} x_{i} x_{j}+\sum_{i=1}^{k} \beta_{i i} x_{i}^{2}+\varepsilon
$$

A first-order design describes a design used in modeling firstorder effect while a second-order design describes a design used in modeling second-order effect. The model matrix $\mathrm{X}$ is built using the model and its associated design, and contains rows synonymous to the model parameters. There exists optimal designs built with respect to some functional of the variance-covariance matrix, $\left(X^{\prime} X\right)^{-1}$. In the theory of optimal design of experiments, such designs are considered optimal only with respect to a specified optimality criterion. They include designs that may be constructed to minimize the determinant of the variance-covariance matrix. By so doing, the least square estimates of the parameters are as precise as possible. The general concept is that such designs are model dependent. Hence, designs optimal for one model need not be optimal for another model. Although much of the literature in optimal design of experiments assume the regression model is a 
full polynomial model, sometimes, missing- or varyingcoefficients of a polynomial could occur due to modifications of the underlying full model (Huang et al.[5], Bon[1] ). It is possible to delete some selected terms of the full model if the experimenter knows that they are unimportant for the response. Also the experimenter may merely be interested in investigating the effect of deleting some model terms. Toh et al. [11] observed that for highdimensional and high-order problems, multivariate polynomial regression becomes impractical due to huge number of product terms and thus proposed the use of reduced multivariate polynomial model to overcome dimensionality problem. Fan and Zhang [3] gave a comprehensive review of various statistical procedures proposed for many varying coefficient models. Sometimes, some of the model coefficients are relaxed in other to verify some statistical theorems (Zhu et al. [14], Yuan et al. [13]). Iwundu and Albert-Udochukwuka [6] considered the behaviour of D-optimal exact designs for first-order polynomial models under changing regression polynomials. Both full polynomial models and reduced polynomial models are extensively studied in the literature on designing experiments. Reduced models are common in unreplicated factorial experiments, when error estimates are unavailable and it becomes necessary to pool information on certain high order interaction terms to make up information on the error term. The aim of this research is to study the precision of full polynomial response surface designs on models with missing coefficients. We shall, in this work, refer to models having missing coefficients as reduced models.

In studying the precision of full polynomial response surface designs on models with missing coefficients, design efficiency shall be employed to assess the quality of the designs. Commonly encountered measures of efficiency of designs are the D-and Gefficiency. Each of them is a numeric measure that qualifies the precision or efficiency of the designs.

According to Crosier [2], D-efficiency is the $\mathrm{p}^{\text {th }}$ root of the ratio of $\frac{\operatorname{det}\left(X^{\prime} X\right)}{{ }_{N}^{p}}$ to the maximum possible value of $\frac{\operatorname{det}\left(X^{\prime} X\right)}{{ }_{N}^{p}}$ for any design defined on the same region. On the other hand, the Gefficiency of a design is defined as

$$
\frac{\mathrm{p}}{\mathrm{V}(\underline{\mathrm{x}})_{\max }}
$$

where $\mathrm{p}$ is the number of parameters in the model and $\mathrm{V}(\underline{\mathrm{x}})_{\max }$ is the maximum scaled variance of prediction. As can be seen in Myer et al. [9] the variance of the function at $\underline{\mathrm{x}}$ is

$\mathrm{V}(\hat{\mathrm{y}}(\underline{\mathrm{x}}))=\frac{\mathrm{V}(\underline{\mathrm{x}}) \sigma^{2}}{\mathrm{~N}}$

where $\mathrm{V}(\underline{\mathrm{x}})=\mathrm{N}_{\underline{\underline{x}}}{ }^{\prime}\left(\mathrm{X}^{\prime} \mathrm{X}\right)^{-1} \underline{\underline{\mathrm{x}}}$ is the scaled variance for any point $\underline{\mathrm{x}}$ in the design region.

Thus,

$\operatorname{Var}(\hat{\mathrm{y}}(\underline{\mathrm{x}}))=\underline{\underline{x}}^{\prime} \mathrm{M}^{-1} \underline{\underline{\mathrm{x}}}$.

The vector $\underline{\underline{x}}$ is the row vector of the design matrix, $\mathrm{X}$, associated with the design point $\underline{x}$.

G-efficiency thus examines the maximum value of $\mathrm{V}(\underline{\mathrm{x}})=\frac{\operatorname{NVar}[\hat{\mathrm{y}}(\mathrm{x})]}{\sigma^{2}}$ within the design region with respect to its theoretical minimum variance $\mathrm{p}$. Onukogu [10] has proven, using equivalence relation of D- and G-optimality criteria, that the theoretical minimum variance is $\mathrm{p}$. Without loss in generality $\sigma^{2}=1$. Crosier [2] noted that although it is possible to have a design with a high D-efficiency and a low G-efficiency but not vice versa and offered G-efficiency of $50 \%$ or more as a practical rule for choosing a good design. Condition numbers of designs have also been utilized in comparing competing designs (see Iwundu and AlbertUdochukwu [6] ).The condition number of a pxpnon-singular square symmetric matrix, $\mathrm{M}$, associated with a design and having elements, $m_{i j}$, such that $m_{i j}=m_{j i}$, is defined in terms of a matrix norm by $\operatorname{Cond}(\mathrm{M})=\|\mathrm{M}\| .\left\|\mathrm{M}^{-1}\right\|$. The matrix norm $\|\mathrm{M}\|$ can easily be computed as the maximum absolute column sum (or row sum) given by

$\|\mathrm{m}\|=\max _{\mathrm{j}} \sum_{\mathrm{i}=1}^{\mathrm{p}}\left|\mathrm{m}_{\mathrm{ij}}\right| ;\|\mathrm{m}\|>0$ if $\mathrm{m} \neq 0$

The matrix norm $\left\|\mathrm{M}^{-1}\right\|$ is similarly computed.

For any matrix $\mathrm{M}$, Cond $(\mathrm{M}) \geq 1$. A design with condition number of 1 is orthogonal, while a design with increased condition number is less orthogonal. Hence, designs with low condition numbers shall be preferred to designs with higher condition numbers.

\section{Methodology}

In an attempt to investigate the precision of full polynomial response surface designs on reduced models, the full polynomial response surface designs shall be those constructed to minimize the determinants of the variance-covariance matrices associated with the polynomial. The reduced model shall be those for which the highest order interaction term is assumed not present. Thus the full (complete) two-variable first-degree model is

$\mathrm{y}=\beta_{0}+\beta_{1} \mathrm{x}_{1}+\beta_{2} \mathrm{x}_{2}+\beta_{12} \mathrm{x}_{1} \mathrm{x}_{2}+\varepsilon$

The reduced two-variable first-degree model is

$\mathrm{y}=\beta_{0}+\beta_{1} \mathrm{x}_{1}+\beta_{2} \mathrm{x}_{2}+\varepsilon$

The complete two-variable second-degree model is

$$
y=\beta_{0}+\beta_{1} x_{1}+\beta_{2} x_{2}+\beta_{12} x_{1} x_{2}+\beta_{11} x_{1}^{2}+\beta_{22} x_{2}^{2}+\varepsilon
$$

And the corresponding reduced two-variable second-degree model is

$$
y=\beta_{0}+\beta_{1} x_{1}+\beta_{2} x_{2}+\beta_{11} x_{1}^{2}+\beta_{22} x_{2}^{2}+\varepsilon
$$

The choice of the models is due to the fact that in many practical problems, low order polynomials are used to approximate the true unknown functional relationship between the response variable and the control variables. The design region for exploration is the two-dimensional Euclidean plane bounded by $-1 \leq \mathrm{x}_{1}, \mathrm{x}_{2} \leq 1$. The design size $\mathrm{N}$ lies in the interval $\mathrm{p} \leq \mathrm{N} \leq \frac{1}{2} \mathrm{p}(\mathrm{p}+1)+1$ (Fedorov[4]). An N-point exact design can be represented by a matrix $\mathrm{D}$, of order $\mathrm{N} \times \mathrm{k}$

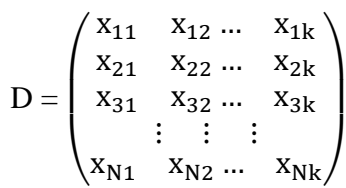

where $\mathrm{x}_{\mathrm{ij}}$ denotes the $(\mathrm{ij})^{\text {th }}$ design setting $; \mathrm{i}=1,2, \ldots, \mathrm{k} ; \mathrm{j}=$ $1,2, \ldots, N$. Each row of $\mathrm{D}$ represents a point, referred to as a design point, in a k-dimensional Euclidean space. The exact designs are obtained according to the rules of Wynn [12] and Iwundu and Chigbu [7]. As is usual in optimal designs theory, the model matrix, $\mathrm{X}$, shall be formed using the design and the model as an $\mathrm{N} \times \mathrm{p}$ matrix whose columns correspond to the terms in the model. For 
example, the model matrix associated with the N-point exact design of order $\mathrm{N} \times 2$ for the model in (6) is

$\mathrm{X}=\left(\begin{array}{cccc}1 \mathrm{x}_{11} & \mathrm{x}_{12} & \ldots & \mathrm{x}_{11} \mathrm{x}_{12} \\ 1 \mathrm{x}_{21} & \mathrm{x}_{22} & \ldots & \mathrm{x}_{21} \mathrm{x}_{22} \\ 1 \mathrm{x}_{31} & \mathrm{x}_{32} & \ldots & \mathrm{x}_{31} \mathrm{x}_{32} \\ & \vdots & \vdots & \vdots \\ 1 \mathrm{x}_{\mathrm{N} 1} & \mathrm{x}_{\mathrm{N} 2} & \ldots & \mathrm{x}_{\mathrm{N} 1} \mathrm{x}_{\mathrm{N} 2}\end{array}\right)$

$\mathrm{X}^{\prime} \mathrm{X}$ shall define the information matrix of the design which shall be normalized as

$\mathrm{M}=\frac{\mathrm{X}^{\prime} \mathrm{X}}{\mathrm{N}}$

Normalizing the information matrix helps to remove the effect of varying design size, $\mathrm{N}$ so that comparisons may be made. Each first- order design shall be expanded into a model matrix such that for every non-singular information matrix, $\mathrm{M}$, a determinant value may be computed, assuming the respective full and reduced firstorder design models. Similarly each second-order design shall be expanded into a model matrix and an associated determinant value of information matrix may also be computed assuming the respective full and reduced second-order models. The scaled variance of prediction at each design point shall be obtained using the designs and the models. Design efficiency and condition number shall be employed to assess the quality of the designs. The use of D-and Gefficiency as fundamental measures of quality of designs is common in vast numbers of literatures and these shall be the chosen efficiency criteria for use in this research. Efficiency values lie between 0 and 1 when a design, $\xi_{\mathrm{N}}$, is compared to a reference design, $\xi_{\mathrm{N}}^{*}$, usually an optimal design. The values may be presented in percentage for easy interpretation. We shall compare the efficiency of the design when defined for the reduced models in relation to the efficiency of the design when defined for the full models. A design shall be considered more suitable for a particular model if it has a higher efficiency value for that model than when used for the competing model. The loss in efficiency, which is simply one minus efficiency, shall be computed to compare the suitability of the first-and second-order designs for the reduced models. Furthermore, comparison shall be made using the condition numbers of the design.

\section{Results}

For the first-order full model, the 4-point exact design constructed to maximize the determinant of information matrix is

$\xi_{4}=\left[\begin{array}{cc}1 & 1 \\ 1 & -1 \\ -1 & 1 \\ -1 & -1\end{array}\right]$

For $\mathrm{N}=5,6 \ldots 11$, the design points that make up the exact designs are as in Table 1

Table 1: First-Order N-Point Exact Designs for $\mathrm{N}=5,6 \ldots 11$

\begin{tabular}{ll}
\hline Design size & Design points \\
\hline 5 & $\xi_{4}+(1,1)$ \\
6 & $\xi_{5}+(1,-1)$ \\
7 & $\xi_{6}+(-1,1)$ \\
8 & $\xi_{7}+(-1,-1)$ \\
9 & $\xi_{8}+(1,1)$ \\
10 & $\xi_{9}+(1,-1)$ \\
11 & $\xi_{10}+(-1,1)$ \\
\hline
\end{tabular}

For the second-order full model, the 6-point exact design constructed to maximize the determinant of information matrix is

$$
\xi_{6}=\left[\begin{array}{cc}
1 & 1 \\
1 & -1 \\
-1 & 1 \\
-1 & -1 \\
1 & 0 \\
0 & 0
\end{array}\right]
$$

For $\mathrm{N}=7,8 \ldots 22$, the design points that make up exact designs are as in Table 2.

Table 2: Second-Order N-Point Exact Designs for $\mathrm{N}=5,6 \ldots 11$

\begin{tabular}{llll}
\hline Design size & Design points & Design size & Design points \\
\hline 7 & $\xi_{6}+(0,-1)$ & 15 & $\xi_{14}+(-1,0)$ \\
8 & $\xi_{7}+(-1,0)$ & 16 & $\xi_{15}+(1,1)$ \\
9 & $\xi_{8}+(0,1)$ & 17 & $\xi_{16}+(1,-1)$ \\
10 & $\xi_{9}+(1,1)$ & 18 & $\xi_{17}+(-1,1)$ \\
11 & $\xi_{10}+(1,-1)$ & 19 & $\xi_{18}+(-1,-1)$ \\
12 & $\xi_{11}+(-1,1)$ & 20 & $\xi_{19}+(0,1)$ \\
13 & $\xi_{12}+(-1,-1)$ & 21 & $\xi_{20}+(1,0)$ \\
14 & $\xi_{13}+(0,0)$ & 22 & $\xi_{21}+(0,-1)$ \\
\hline
\end{tabular}

The full first-order model matrix that corresponds to the 4-point exact design is formed as an Nxp design matrix

$$
\mathrm{X}=\left[\begin{array}{rrrr}
1 & 1 & 1 & 1 \\
1 & 1 & -1 & -1 \\
1 & -1 & 1 & -1 \\
1 & -1 & -1 & 1
\end{array}\right]
$$

The associated information matrix is

$$
X^{\prime} X=\left[\begin{array}{llll}
4 & 0 & 0 & 0 \\
0 & 4 & 0 & 0 \\
0 & 0 & 4 & 0 \\
0 & 0 & 0 & 4
\end{array}\right]
$$

The normalized information matrix is

$M=\frac{X^{\prime} X}{4}=\left[\begin{array}{llll}1 & 0 & 0 & 0 \\ 0 & 1 & 0 & 0 \\ 0 & 0 & 1 & 0 \\ 0 & 0 & 0 & 1\end{array}\right]$

Its inverse is

$$
\mathbf{M}^{-1}=\left[\begin{array}{llll}
1 & 0 & 0 & 0 \\
0 & 1 & 0 & 0 \\
0 & 0 & 1 & 0 \\
0 & 0 & 0 & 1
\end{array}\right]
$$

The full second-order model matrix that corresponds to the 6-point exact design is formed as an Nxp design matrix

$$
X=\left[\begin{array}{cccccc}
1 & 1 & 1 & 1 & 1 & 1 \\
1 & 1 & -1 & -1 & 1 & 1 \\
1 & -1 & 1 & -1 & 1 & 1 \\
1 & -1 & 1 & 1 & 1 & 1 \\
1 & 1 & 0 & 0 & 1 & 0 \\
1 & 0 & 0 & 0 & 0 & 0
\end{array}\right]
$$

The information matrix is $X^{\prime} X$ and normalized as $\frac{X^{\prime} X}{6}$.

In a similar fashion, the model matrix that corresponds to the $\mathrm{N}$ point exact design associated with the reduced model is formed, as an Nxp design matrix, by deleting the design matrix column associated with the missing coefficient. 
Using the designs and the models yields the computations in Tables 3-6.

Table 3: Summary of Results Using First-Order Full Model

\begin{tabular}{|c|c|c|c|c|c|c|c|}
\hline $\begin{array}{l}\text { Design } \\
\text { Size } \\
\end{array}$ & $\begin{array}{l}\text { Det } \\
(\mathrm{M}) \\
\end{array}$ & $\begin{array}{l}\text { Max. Var of } \\
\text { Prediction }\end{array}$ & $\begin{array}{l}\text { D- } \\
\text { Efficiency }\end{array}$ & $\begin{array}{l}\text { G- } \\
\text { Efficiency }\end{array}$ & $\begin{array}{l}\text { Loss in D- } \\
\text { Efficiency }\end{array}$ & $\begin{array}{l}\text { Loss in G- } \\
\text { Efficiency }\end{array}$ & $\begin{array}{l}\text { Condition } \\
\text { Number }\end{array}$ \\
\hline 4 & 1.0000 & 4.0000 & 1.0000 & 1.0000 & 0.0000 & 0.0000 & 1.0000 \\
\hline 5 & 0.8192 & 5.0000 & 0.9514 & 0.8000 & 0.0487 & 0.2000 & 2.0000 \\
\hline 6 & 0.7901 & 6.0000 & 0.9428 & 0.6667 & 0.0572 & 0.3333 & 2.0000 \\
\hline 7 & 0.8530 & 7.0000 & 0.9610 & 0.5714 & 0.0390 & 0.4286 & 2.0000 \\
\hline 8 & 1.0000 & 4.0000 & 1.0000 & 1.0000 & 0.0000 & 0.0000 & 1.0000 \\
\hline 9 & 0.9364 & 4.5000 & 0.9837 & 0.8889 & 0.0163 & 0.1111 & 1.5000 \\
\hline 10 & 0.9216 & 5.0000 & 0.9798 & 0.8000 & 0.0202 & 0.2000 & 1.5000 \\
\hline 11 & 0.9442 & 5.5000 & 0.9857 & 0.7273 & 0.0143 & 0.2727 & 1.5000 \\
\hline
\end{tabular}

Table 4: Summary of Results Using First-Order Reduced Model

\begin{tabular}{lllllll}
\hline $\begin{array}{l}\text { Design } \\
\text { Size }\end{array}$ & $\begin{array}{l}\text { Det } \\
(\mathrm{M})\end{array}$ & $\begin{array}{l}\text { Max. Var of } \\
\text { Prediction }\end{array}$ & $\begin{array}{l}\text { D- } \\
\text { Efficiency }\end{array}$ & $\begin{array}{l}\text { G- } \\
\text { Efficiency }\end{array}$ & $\begin{array}{l}\text { Loss in D- } \\
\text { Efficiency }\end{array}$ & $\begin{array}{l}\text { Loss in G- } \\
\text { Efficiency }\end{array}$ \\
\hline 4 & 1.0000 & 3.0000 & 1.0000 & 1.0000 & 0.0000 & 0.0000 \\
5 & 0.8960 & 3.5714 & 0.9641 & 0.8400 & 0.0359 & 0.1600 \\
6 & 0.8889 & 4.0000 & 0.9615 & 0.7500 & 0.0290 & 0.2500 \\
7 & 0.9329 & 4.2000 & 0.9771 & 0.7143 & 0.0172 & 0.2857 \\
8 & 1.0000 & 3.0000 & 1.0000 & 1.0000 & 0.0000 & 0.0000 \\
9 & 0.9657 & 3.2727 & 0.9884 & 0.9167 & 0.0116 & 0.0833 \\
10 & 0.9600 & 3.5000 & 0.9865 & 0.8571 & 0.0135 & 0.1429 \\
11 & 0.9737 & 3.6667 & 0.9912 & 0.8182 & 0.0084 & 1.3750 \\
\hline
\end{tabular}

\begin{tabular}{|c|c|c|c|c|c|c|c|}
\hline $\begin{array}{l}\text { Design } \\
\text { Size }\end{array}$ & $\begin{array}{l}\text { Det } \\
(\mathrm{M})\end{array}$ & $\begin{array}{l}\text { Max. Var of } \\
\text { Prediction }\end{array}$ & $\begin{array}{l}\text { D- } \\
\text { Efficiency }\end{array}$ & $\begin{array}{l}\text { G- } \\
\text { Efficiency }\end{array}$ & $\begin{array}{l}\text { Loss in D- } \\
\text { Efficiency }\end{array}$ & $\begin{array}{l}\text { Loss in G- } \\
\text { Efficiency }\end{array}$ & $\begin{array}{l}\text { Condition } \\
\text { Number }\end{array}$ \\
\hline 6 & 0.0055 & 6.0000 & 0.8869 & 1.0000 & 0.1131 & 0.0000 & 48.6927 \\
\hline 7 & 0.0082 & 6.8833 & 0.9480 & 0.8717 & 0.0520 & 0.1283 & 20.1766 \\
\hline 8 & 0.0088 & 7.3333 & 0.9592 & 0.8182 & 0.0408 & 0.1818 & 20.7295 \\
\hline 9 & 0.0098 & 7.2500 & 0.9765 & 0.8276 & 0.0235 & 0.1724 & 18.0000 \\
\hline 10 & 0.0094 & 8.0513 & 0.9698 & 0.7452 & 0.0302 & 0.2548 & 20.9754 \\
\hline 11 & 0.0095 & 8.7396 & 0.9715 & 0.6865 & 0.0285 & 0.3135 & 23.0779 \\
\hline 13 & 0.0113 & 6.8824 & 1.0000 & 0.8718 & 0.0000 & 0.1282 & 26.2266 \\
\hline 14 & 0.0110 & 6.2462 & 0.9955 & 0.9606 & 0.0045 & 0.0394 & 17.6356 \\
\hline 15 & 0.0106 & 6.5665 & 0.9894 & 0.9137 & 0.0106 & 0.0863 & 18.2293 \\
\hline 16 & 0.0103 & 7.0026 & 0.9847 & 0.8568 & 0.0153 & 0.1432 & 19.8417 \\
\hline 17 & 0.0103 & 7.2357 & 0.9847 & 0.8292 & 0.0153 & 0.1708 & 21.2628 \\
\hline 18 & 0.0104 & 7.6549 & 0.9863 & 0.7838 & 0.0137 & 0.2162 & 22.6459 \\
\hline 19 & 0.0107 & 7.5220 & 0.9909 & 0.7977 & 0.0091 & 0.2023 & 23.8925 \\
\hline 20 & 0.0110 & 7.0005 & 0.9955 & 0.8571 & 0.0045 & 0.1429 & 22.7099 \\
\hline 22 & 0.0113 & 6.2756 & 1.0000 & 0.9561 & 0.0000 & 0.0439 & 21.9930 \\
\hline
\end{tabular}

Table 6: Summary of Results Using Second-Order Reduced Model

\begin{tabular}{|c|c|c|c|c|c|c|c|}
\hline $\begin{array}{l}\text { Design } \\
\text { Size }\end{array}$ & $\begin{array}{l}\text { Det } \\
(\mathrm{M})\end{array}$ & $\begin{array}{l}\text { Max. Var of } \\
\text { Prediction }\end{array}$ & $\begin{array}{l}\text { D- } \\
\text { Efficiency }\end{array}$ & $\begin{array}{l}\text { G- } \\
\text { Efficiency }\end{array}$ & $\begin{array}{l}\text { Loss in D- } \\
\text { Efficiency }\end{array}$ & $\begin{array}{l}\text { Loss in G- } \\
\text { Efficiency }\end{array}$ & $\begin{array}{l}\text { Condition } \\
\text { Number }\end{array}$ \\
\hline 6 & 0.0082 & 6.0000 & 0.8216 & 0.8333 & 0.1784 & 0.1667 & 48.6927 \\
\hline 7 & 0.0143 & 5.1333 & 0.9183 & 0.9740 & 0.0817 & 0.0260 & 20.1766 \\
\hline 8 & 0.0176 & 5.3333 & 0.9572 & 0.9375 & 0.0428 & 0.0625 & 20.7295 \\
\hline 9 & 0.0219 & 5.0000 & 1.0000 & 1.0000 & 0.0000 & 0.0000 & 18.000 \\
\hline 10 & 0.0202 & 5.4762 & 0.9840 & 0.9130 & 0.0160 & 0.0870 & 20.6222 \\
\hline 11 & 0.0191 & 5.9583 & 0.9730 & 0.8392 & 0.0270 & 0.1608 & 23.0779 \\
\hline 12 & 0.0186 & 6.4138 & 0.9679 & 0.7796 & 0.0321 & 0.2204 & 24.5367 \\
\hline 13 & 0.0183 & 6.8824 & 0.9647 & 0.7265 & 0.0353 & 0.2735 & 26.2266 \\
\hline 14 & 0.0193 & 6.2462 & 0.9750 & 0.8005 & 0.0250 & 0.1995 & 17.6356 \\
\hline 15 & 0.0198 & 6.4468 & 0.9800 & 0.7756 & 0.0200 & 0.2244 & 18.2293 \\
\hline 16 & 0.0188 & 6.8201 & 0.9699 & 0.7331 & 0.0301 & 0.2669 & 19.7460 \\
\hline 17 & 0.0181 & 6.9988 & 0.9626 & 0.7144 & 0.0374 & 0.2856 & 21.2628 \\
\hline 18 & 0.0175 & 7.3969 & 0.9561 & 0.6760 & 0.0439 & 0.3240 & 22.5565 \\
\hline 19 & 0.0170 & 7.5220 & 0.9506 & 0.6647 & 0.0494 & 0.3353 & 23.8925 \\
\hline 20 & 0.0184 & 7.0005 & 0.9658 & 0.7142 & 0.0342 & 0.2858 & 22.7099 \\
\hline 21 & 0.0194 & 7.1806 & 0.9760 & 0.6963 & 0.0240 & 0.3037 & 22.7028 \\
\hline 22 & 0.0209 & 5.9231 & 0.9907 & 0.8442 & 0.0093 & 0.1558 & 21.9930 \\
\hline
\end{tabular}

\section{Discussions}

The choice of the design size is restricted to

$\mathrm{p} \leq \mathrm{N} \leq \frac{1}{2} \mathrm{p}(\mathrm{p}+1)+1$ as in many literatures on optimal design of experiments. For the $\mathrm{N}$-point exact designs considered, both D- and G-efficiency values were generally high for designs defined for either the full model or the reduced model. Although for first-order models, it is in agreement with Crosier [2] that a design with high D-efficiency value could have low G-efficiency value but not vice versa, variation existed for second-order models as two designs considered had Gefficiency values that were greater than their corresponding D- 
efficiency values. In studying the precision of using constructed full model designs on reduced models, the first-order designs had lower loss in D-efficiency as well as G-efficiency when used on reduced first-order model. However, the second-order designs had more preferences for D- and G-efficiency when used for secondorder full model. The loss in D- and G-efficiency were generally higher for the reduced model. In all cases considered, the Gefficiency values exceeded the minimum $50 \%$ given by Crosier [2] for assessing a good design. In respect to orthogonality criterion, lower condition numbers were observed for the designs under the first-order reduced models. This means that the $\mathrm{N}$-point exact designs were closer to being orthogonal for the reduced model than for the full model. Perfect orthogonality was achieved at $\mathrm{N}=$ 4 and 8 . In fact, for multiples of $4, \mathrm{~N}$-point exact designs have perfect orthogonality when defined either for the full or reduced first-order models. The best first-order designs observed under Dand G-efficiency were also best under the condition number criterion. The condition numbers for second-order designs were large both for full and reduced model. Most of them were identical for the N-point designs defined for both full and reduced models. However, a few cases were observed with slight differences in magnitude and in favour of the second-order reduced model. In comparison to a design with perfect orthogonality, the secondorder designs are far from being orthogonal.

\section{Conclusion}

In using designs optimal for the full first- or second-order models for the reduced no-interaction models, no much loss in D- and Gefficiency was incurred. Results were more precise when the constructed first-order designs were used on the reduced model. This was not generally true for second-order models. In fact, preferences were directed towards the full second-order model. The efficiency values were high enough in all cases studied. The assertion that it is possible to have a design with a high D-efficiency and a low G-efficiency but not vice versa did not hold very absolutely.

\section{References}

[1] J. E. Bon, Generating exact D-optimal designs for polynomial model, SpringSim, 2 (2007) 121-126.

[2] R. B. Crosier, Response Surface design comparisons: Technical Report. U. S. Army Edgewood Research, Development and Engineering Center, SCBRD-RTM, Bldg. E3160 Aberdeen Proving ground, Maryland, MD 21010-5423 (1993).

[3] J. Fan, W. Zhang, Statistical methods with varying coefficient models, Statistics and its Interface, 1(2008) 179-195. https://doi.org/10.4310/SII.2008.v1.n1.a15.

[4] V. V. Fedorov, Theory of Optimal Experiments, Academic Press, New York, 1972.

[5] M. L. Huang, F. Chang, W. K. Wong, D-optimal designs for polynomial regression without an intercept. Statistica Sinica, 5 (1995) 441-458.

[6] M. P. Iwundu, E. B. Albert-Udochukwuka, On the Behaviour of DOptimal Exact Designs Under Changing Regression Polynomials, International Journal of Statistics and Probability, 3(4)(2014) 67-85. doi:10.5539/ijsp.v3n4p67 http://dx.doi.org/10.5539/ijsp.v3n4p67.

[7] M. P. Iwundu, P. E. Chigbu, A hill-climbing Combinatorial Algorithm for constructing N-point D-optimal exact designs, Journal of Statistics Applications and Probability, 1(2) (2012) 133-146. https://doi.org/10.12785/jsap/010205

[8] A. I. Khuri, S. Mukhopadhyay, Response Surface Methodology: Advanced Review, WIREs Computational Statistics, 2 (2010)128 149. https://doi.org/10.1002/wics.73.

[9] R. H. Myers, D. C. Montgomery, C. M. Anderson-Cook, Response Surface Methodology: Process and Product Optimization using designed experiments, 3rd Edition, John Wiley \& Sons, Inc. New Jersey, 2009.

[10] I. B. Onukogu, Foundation of optimal exploration of response surfaces, Ephrata Press, Nsukka, Nigeria, 1997.

[11] K. Toh, W. Yah, X. Jiang, A reduced multivariate polynomial model for Multivariate Biometrics and Classifiers fusion, IEEE Trans- actions on Circuits and Systems for video technology, 14(2) (2004) 224-233. https://doi.org/10.1109/TCSVT.2003.821974.

[12] H. P. Wynn, The sequential generation of D-optimal experimental designs, The Annals of Mathematical Statistics, 41(5) (1970) 1655 1664. https://doi.org/10.1214/aoms/1177696809.

[13] Y. Yuan, H. Zhu, M. Styner, J. H. Gilmore, J. S. Marron, Varying coefficient model for modeling diffusion tensors along white matter tracts, Annals of Applied Statistics, 7(1) (2013) 102-125. https://doi.org/10.1214/12-AOAS574

[14] H. Zhu, R. Li, L. Kong, Multivariate varying coefficient model for functional Responses, Annals of Statistics, 40(5) (2012)2634-2666. https://doi.org/10.1214/12-AOS1045. 